other $(0.06 \%)$ respectively. The prevalence of suspected pulmonary TB were $0.52 \%, 0.50 \%$, and $0.2 \%$ in Cambodian, Burmese, and Lao respectively. The prevalence of positive urine test for methamphetamine was $0.03 \%$.

Discussion The results of this study demonstrate that health problems in workers may be the cause of the spread of TB in Thailand. Reducing the current barriers by providing more complete registration coverage, better provision of healthcare information and active surveillance for $\mathrm{TB}$ among migrant workers may lead to better TB control.

\section{TOWARDS AN EXPERT CONSENSUS ON THE DEVELOPMENT OF OCCUPATIONAL SAFETY AND HEALTH IN KENYA}

Mbusiro Chacha*, Jonathan Houdmont. University of Nottingham, Nottingham, UK

\subsection{6/oemed-2018-ICOHabstracts.904}

Introduction There is an existing knowledge gap in occupational health and safety practice in Kenya. The scarcity of comprehensive research on health and safety and emerging trends in the field evidences this gap. Lack of awareness of health and safety issues has posed a major challenge in the management of health and safety at work. As a result, some organisations have adopted a culture that does not necessarily prioritise occupational health and safety. The purpose of this research is to explore workplace health and safety practitioners' views on future priorities regarding the development of occupational health and safety in Kenya. Specifically, the research objectives are to: identify priorities for improving occupational safety and health, identify strategies to prevent or minimise the hazard exposure, and identify initiatives that will support and create awareness of occupational safety and health in Kenya.

Method This study adopted a qualitative design. Twelve participants were recruited for this study. These individuals were identified as occupational safety and health experts on the basis of a listing on the register of national occupational safety and health advisers produced by the Directorate of Occupational Health and Safety Services (DOSHS) in Kenya. An interview schedule designed to be delivered online was constructed in order to explore health and safety practitioners' views on current occupational health and safety challenges and future priorities in Kenya. Data were analysed using thematic analysis.

Results The thematic analysis of the interviews resulted in the identification of four main themes;

i. disease and accident control,

ii. health and safety promotion,

iii. leadership and management role,

iv. future of occupational safety and health.

Discussion There are challenges facing workplace health and safety in Kenya that need to be addressed. Identification of key priorities in addressing the challenges may contribute to improving the management and practice of health and safety in the workplace.

\section{8 OCCUPATIONAL HEALTH (OH) IN SOUTH AFRICAN CONSTRUCTION}

John Smallwood*, Claire Deacon. Nelson Mandela Metropolitan University, Port Elizabeth, South Africa

\subsection{6/oemed-2018-ICOHabstracts.905}

Introduction Health hazards in construction include: ergonomic stresses such as bending, lifting and repetitive movement and vibration; environmental stresses such as heat, sun, noise, poor illumination, and wet or damp work; skin and respiratory exposure to chemicals and dust, as well as mental stress among managers, supervisors, and workers. In South Africa, these may add to the health problems experienced by construction workers because of poor community health, substance abuse, and inadequate health services.

Methods A self-administered questionnaire survey was conducted among members of a professional construction health and safety management association to determine, inter alia, the extent of $\mathrm{OH}$ problems, $\mathrm{OH}$ perceptions, practices, and interventions, and necessary $\mathrm{OH}$ interventions.

Results Findings include: ergonomic problems followed by exposure to the sun predominated among $\mathrm{OH}$ problems; $\mathrm{OH}$ interventions conducted most frequently include blood testing, HIV and AIDS, and TB education; welfare facilities need to be improved; more personal protective equipment (PPE) needs to be provided; the physical nature of construction needs to be reduced; more information regarding hazardous materials and activities, and disease is required, and more worker training and participation is required.

Discussion The findings resonate with the literature in that $\mathrm{OH}$ is not afforded the status afforded to safety; the degree of $\mathrm{OH}$ knowledge and awareness is limited as opposed to extensive; the source of $\mathrm{OH}$ knowledge is informal; there is a need for $\mathrm{OH}$ to be embedded in tertiary built environment programmes, $\mathrm{OH}$ continuing professional development (CPD), and a construction industry $\mathrm{OH}$ standard, and $\mathrm{OH}$ practice notes.

\section{THE OCCUPATIONAL SAFETY \& HEALTH (OSH) IN INDIA: THE CURRENT SCENARIO}

Priyanka Roy*. Department of Labour, Government of West Bengal, India

\subsection{6/oemed-2018-ICOHabstracts.906}

Introduction Occupational Safety and Health $(\mathrm{OSH})$ is an important for the health and well being of the workers to ensure the hazard free workplace, reduces absenteeism and enhancing the productivity by properly addressing the safety and health issues of the employees. Though India has reached to high rate of growth due to industrialization over the period, the challenge continues to ensure the OSH culture at workplace.

Methods This is an analysis of all Government documents related to Labour Act of India. Total 51 documents were retrieved from the Ministry of Labour and Employment (India) website with a search strategy. All documents were classified into 7 themes: industrial relations; wages; working 